\title{
Preparations and Characterizations of Carboxymetylated Hydrophilic Macromolecular Composites Directly Derived from Weeds
}

\author{
Mitsuru Aoyagi ${ }^{1 *}$, Kento Maesono $^{1}$ \\ 1 Faculty of Biological and Environmental Sciences, Prefectural University of Hiroshima, \\ 562 Nanatsuka-cho, Shobara, Hiroshima, 724-0023 \\ * Corresponding author: e-mail: aoyagi@pu-hiroshima.ac.jp
}

\begin{abstract}
Direct carboxymethylations for aliphatic hydroxyl groups in weeds such as Tall fescue (Festuca arundinacea, TF), Sweeping lovegrass (Eragrostis curvula, SL) and Canada goldenrod (Solidago Canadensis, CG) were carried out in 2-propanol / $30 \% \mathrm{NaOH}$ at $55{ }^{\circ} \mathrm{C}$ for $3.5 \mathrm{hrs}$. Under the typical conditions, carboxyletylated TF (TF-CM), SL-CM and CG-CM were obtained at yields of $145 \%, 135 \%$ and $148 \%$ based on each dry weight of lignocellulosics, respectively. Although degrees of substitutions of these $\mathrm{CM}$ materials were only small values such as $0.08-0.11$, almost all materials were easily dissolved into water. Structural features were investigated using FT-IR and UV-Vis. Visocosities of $1 \%(\mathrm{w} / \mathrm{w})$ aqueous solutions or suspensions of $\mathrm{CM}$ derivatives were measured by vibrating viscometer under different temperatures and $\mathrm{pH}$. Since there are differences on viscosities between TF and CG in spite of same degrees of substitution, properties were different due to different structures of plant tissues.
\end{abstract}

Key words: Lignocellulosics, Carboxymethylation, Weeds, Hydrophillic Composite

\section{INTRODUCTION}

Lignocellulose is well known as macromolecular composites in plant cell walls with lignin and carbohydrates such as cellulose and hemicellulose. This material is expected as circulating carbon resources with high recyclability based on both biodegradability and ability of regeneration through photosynthesis.

Lignocellulose has been utilized as essential materials for our lives such as fibers, ropes, roof materials and fuels since ancient periods. Within a few hundred years, chemical utilization of lignocellulose such as a paper pulp production has been discovered drastically. More recently, accumulated residue from both industrial and agricultural crops such as bagasse or empty fruit bunch of oil palm has been attracted as circulating organic materials because of crisis on depletion of fossil carbon resources. But it has been difficult to be utilized these raw materials as substitutions of petroleum or coals, because of low efficiency on transportation of these accumulation, which is one of the most important factors on the economic aspects on utilization as carbon resources. In addition, energy profit ratio (EPR), which is one of important indicators for values of resources, of these raw materials including lignocellulose is inferior to fossil carbon resources. For reasons mentioned above, it has been difficult to be utilized these accumulations of these herbal materials with both light weights and low energy densities as energy sources. Therefore, these materials should be utilized as raw materials for organic composites rather than as energy sources.

A weed is defined a natural herbal plant, which lives independent from human society. In general, there are only a few merits such as a raw material for medicines or for seasonal foods in local daily lives. Although these plants live in everywhere on the wet land space on the earth, only wild plants which live on the boundaries between nature and human society, such as on side spaces of traffic road, parks or public gardens can be utilized because of difficulty in harvest. Usually, these plants produced negative influences on human activities. For example, wild animals and insects, which are often causes of traffic accidents, are usually invaded into road along the shade of these weeds. In addition, fire accidents along traffic roads and in the parks are also happened on dried weeds. Therefore, in a lot of cases in Japan, these wild plants are harvested at fixed intervals by local governments in order to keep a traffic safety and a clean environment. In almost all cases, the harvests activities are carried out by local offices using public budgets in Japan because several relating problems around these plans have been accepted as public risks, mentioned above. For example, Shobara city in Hiroshima prefecture in Japan, that is one of the typical local cities in Japan, has spent $c a .20$ million yen per year in 2016 for harvesting wild plants living around public spaces or by the roadside. Though the harvests activities of these renewable raw materials are carried out every season, all plant materials were burned out as industrial wastes without any utilization. Since burning out of these lignocelluloses are both wastes of circulating materials by short-cut to $\mathrm{CO}_{2}$ gas and wastes of public assets, these plant materials have been expected to be utilized.

Here, focusing on an EPR value of these harvests again, relatively high values are expected based on low costs of both conveyance and integration through public achievements. In fact, problems on material utilization of grass materials are these high costs based on low density compared to woody materials in both substances and energy. In addition, taking chemical utilization into considerations, grass materials have higher advantages than woody materials with rough lignocellulosic matrix in cell walls because of easy separation of components.

Carboxymethylation (CM reactions) is one of the most useful reactions on hydroxyl groups for derivations of hydrophilic macromolecules. These hydrophilic macromolecules based on cellulosic materials such as carboxymethylcellulose (CMC) have been attracted as 


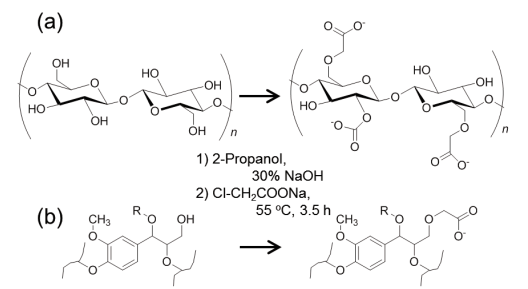

Fig. 1 Scheme for carboxymethylation of (a) cellulose and (b) lignin. This scheme shows that only a half of hydroxyl groups in cellulose are reacted in (a). $\mathrm{R}=\mathrm{H}$, Ar or alkylgroups.

industrial materials such as chemicals, food additives, molds, paints, adhensives. In general, high quality paper pulps from woods have been used as raw materials for CMC. In addition, CM reactions have also utilized as one of major techniques to increase hydrophilicity of hydrophobic macromolecules such as lignins. For example, carboxymethylated lignin materials have also been investigated to improve properties. CM reactions of lignophenols, which are designed phenolic native lignin derivatives, have been developed for medical reagents such as inhibitors for HIV or swelling hydrophilic gels [1-2].For these reasons, chemical utilization of weeds live along traffic roads or in public spaces was tried through direct $\mathrm{CM}$ reactions for these lignocellulose without pulping process.

Recently, Chien et al has reported trials on fractionation of macromolecular compositions in Aspen (Populus tremula) and Norway spruce (Picea abies) through CM reactions [3]. Moreover, Ren et al reported detail spectroscopic analyses for $\mathrm{CM}$ derivatives of agricultural grass materials [3]. In addition, Ren et al also reported phenolic moieties in lignin precursors showed relatively low reactivity for CM reactions [4]. Therefore, investigation for physical properties of direct $\mathrm{CM}$ materials is required information of influences of phenolic hydroxyl groups.

In this study direct $\mathrm{CM}$ reactions for lignocellulosics in three weeds, Tall fescue (Festuca arundinacea), Sweeping lovegrass (Eragrostis curvula) and Canada golden rod (Solidago canadensis) and investigations on physical properties of resulting $\mathrm{CM}$ derivatives in aqueous solutions or water dispersions were carried out using vibration viscometer under different temperatures, $\mathrm{pH}$ and concentrations.

\section{EXPERIMENTAL}

2.1. Sampling of wild grass materials

Tall fescue (TF, Festuca arundinacea) was collected on July 14th 2014 at a field along prefectural road No.442 in Nanatsuka-cho (N:34.5, E: $132.6^{\circ}$ ), Shobara city, Hiroshima, Japan. And both Weeping lovegrass (WLG, Eragrostis curvula) and Canada golden rod (CG, Solidago canadensis) were also collected on November 12th 2014 at the same location. Only stems of these plants were well dried at r.t. and used for synthesis. These stems were cut and then were well crushed by Labomillcer (Osaka Rika Co, JAPAN). Resulting powders of lignocellulosics were separated using SUS mesh $(250 \mu \mathrm{m})$. The 60 mesh-passed samples were used for experiments.

\subsection{Analysis for fundamental chemical compositions}

To evaluate fundamental chemical compositions in stems of plants, several parameters were estimated following JIS standards in duplicate experiments. The parameters were corresponded to humidity, ash, cold water extraction, hot water extraction, extraction by $1 \%$ alkaline aq. solutions, extraction by ethanol-benzene $(1: 2$, $\mathrm{v}: \mathrm{v})$ under reflux, amounts of holocellulose, lignin contents, $\alpha$ - and $\beta$-cellulosic moieties of these materials.

2.3. Synthesis of carboxymethylated lignocellulosics

$\mathrm{CM}$ reactions for grass materials were carried out following a typical procedure as below [3, 6-9]. Defatted powder (60 mesh passed) of lignocellulosics $(1.0 \mathrm{~g})$ was added into $100 \mathrm{~mL}$ three necked-round bottom flask, and then $15.0 \mathrm{~mL}$ of 2-propanol was poured and stirred well at room temperature. After $30 \mathrm{~min}$ stirring, $20.0 \mathrm{~mL}$ of $30 \% \mathrm{NaOH}$ was added. After a reaction mixture was heated up to $55^{\circ} \mathrm{C}, 100 \mathrm{mg}(1.1 \mathrm{mmol})$ of monochloroacetic acid was gradually added within 30 min. After $3.5 \mathrm{hrs}$, the reaction mixture was washed out using $80 \% \mathrm{MeOH}$ aq. Resulting precipitate was washed by $80 \% \mathrm{MeOH}$ aq using centrifugation $\left(5^{\circ} \mathrm{C}, 3500 \mathrm{rpm}\right.$, 20 min). After air drying and vacuum drying on $\mathrm{P}_{2} \mathrm{O}_{5}$, a sodium salt of CM derivative was obtained as a yellow powder. A yield of CM-Na was determined by the defatted powder. The adequate synthesis conditions were investigated under different conditions such as reaction temperatures $\left(10^{\circ} \mathrm{C}, \quad 40^{\circ} \mathrm{C}, \quad 55^{\circ} \mathrm{C}\right)$, concentrations of $\mathrm{NaOH}(7.5 \%, 15 \%$ and $30 \%)$ and reaction times (5 $\mathrm{min}, 60 \mathrm{~min}$ and $120 \mathrm{~min}$ ). In addition, a $\mathrm{CM}$ reaction for holocellulose of $\mathrm{TF}$ was also prepared through the same procedure.

\subsection{Degree of substitution (DS)}

A degree of substitution (DS) of a CM material was determined using a reverse titration. After a CM material was washed by $\mathrm{MeOH}$ with conc. $\mathrm{HCl}$, carboxyl groups of TF-CM with acid form were titrated using $1.0 \mathrm{M}$ $\mathrm{NaOH}$ with $\mathrm{pH}$ meter (F-21 pH meter with $9621 \mathrm{C} \mathrm{pH}$ electrode, Horiba Co.). The DS value was calculated all materials as cellulose.

\subsection{Viscosity of dispersions of $\mathrm{CM}$ derivatives.}

Aqueous dispersions or solutions $(1 \%$, w./w.) of $\mathrm{CM}$-materials including commercial $\mathrm{CMC}$ and $\mathrm{CM}$ holocellulose of TF were prepared and used for experiments. Measurements of viscosity were carried out using vibrating viscometer (VM-1A, YAMACO Co.) at 10,25 and $40{ }^{\circ} \mathrm{C}$. Viscosity (mPa s) was divided by density of solutions or dispersions.

\section{RESULTS AND DISCUSSIONS}

3.1. Chemical compositions of lignocellulosics

Chemical compositions of TF, WLG and CG were summarized in Table1. There were large differences in amounts of extractives and ash. On the contrary, it was found that there were only small differences in macromolecular contents, such as carbohydrates and lignin. In addition, amounts of $\alpha$-cellulose, which composed of crystal form of cellulose, were almost same amounts. This result implied that macromolecules and their composites show similar properties such as solubility and viscosity. Due to these results, 60 mesh 
Table1 Chemical compositions of weed materials

\begin{tabular}{lccc}
\hline & $\begin{array}{c}\text { Tall } \\
\text { Fescue/\% }\end{array}$ & $\begin{array}{c}\text { Weeping } \\
\text { Lovegrass/\% }\end{array}$ & $\begin{array}{c}\text { Canada } \\
\text { Goldenrod/\% }\end{array}$ \\
\hline Humidity & 8.1 & 7.8 & 7.8 \\
Cold water extractives & 15.8 & 3.5 & 0.7 \\
Hot water extractives & 27.7 & 6.0 & 6.1 \\
$1 \%$ NaOH extractives & 48.6 & 39.5 & 27.0 \\
EtOH-benzene extractives & 11.2 & 0.8 & 0.8 \\
Ash & 4.7 & 1.5 & 1.2 \\
Holocellulose & 77.4 & 79.3 & 89.7 \\
$\quad \alpha-c e l l u l o s e$ & 44.1 & 40.3 & 43.0 \\
$\beta$-cellulose & 2.9 & 1.8 & 1.8 \\
Total Lignin Contents & 18.6 & 23.8 & 22.3 \\
$\quad$ Acid soluble Lignin & 1.5 & 1.5 & 3.3 \\
Klason Lignin & 17.1 & 22.3 & 19.0 \\
\hline
\end{tabular}

Duplicate measurements were carried out for all experiments.

passed grass meals (particle size $<250 \mu \mathrm{m}$ ) of lignocellulosics after removal of extractives were used for synthesis. In addition, not only $\alpha$-cellulose but both $\beta$ - and $\gamma$ - cellulose moieties were included in the materials, which including several hemicellulose such as xylan. As results of $1 \% \mathrm{NaOH}$ extraction showed, a part of hemicellulose was extracted and removed through hydrolysis under a mild alkaline condition. As GC has more abundant lignin contents for about $4 \%$ than $\mathrm{TF}$, it was implied that it was hard to be isolated from lignocellulosic carbohydrates.

\subsection{Characteristics and properties of $\mathrm{CM}$ derivatives}

Results of direct CM reactions on TF, WLG and CG under different conditions were summarized in Table2. The reaction condition of Run1, which showed $143 \%$ yield, was a typical condition $([\mathrm{NaOH}]=20 \%, \mathrm{~T}=55$ ${ }^{\circ} \mathrm{C}, \mathrm{t}=210 \mathrm{~min}$ ). In a case of a glucoside monomeric part in cellulose with three free aliphatic hydroxyl groups $(\mathrm{C} 2-\mathrm{OH}, \mathrm{C} 3-\mathrm{OH}$ and $\mathrm{C} 6-\mathrm{OH})$, an ideal yield of $\mathrm{CM}$ derivatives with only one $-\mathrm{OH}$ group which was converted into a carboxymethyl group showed about $158 \%$ yield as sodium salts in calculation. Also, a monomeric part in a native lignin molecule has only one aliphatic hydroxyl groups such as $\mathrm{C} 9-\mathrm{OH}(\mathrm{C} \gamma-\mathrm{OH})$ will be reacted because of only low amounts of $-\mathrm{OH}$ in native lignin and low reactivity of phenolilc $-\mathrm{OH}$ for $\mathrm{CM}$ reactions [5]. In addition, based on Table1, there were $80 \%$ of carbohydrates and $20 \%$ of lignin in TF

\begin{tabular}{|c|c|c|c|c|}
\hline Run & $\begin{array}{c}\mathrm{NaOH} \\
/ \% \\
\end{array}$ & $\begin{array}{l}\text { Temp. } \\
/{ }^{\circ} \mathrm{C}\end{array}$ & $\begin{array}{l}\text { Reaction } \\
\text { Time / min }\end{array}$ & $\begin{array}{c}\text { Yield }{ }^{1)} \\
/ \%\end{array}$ \\
\hline 1 & 30 & 55 & 210 & 143.2 \\
\hline 2 & 30 & 5 & 210 & 89.2 \\
\hline 3 & 30 & 25 & 210 & 150.2 \\
\hline 4 & 30 & 40 & 210 & 159.3 \\
\hline 5 & 7.5 & 55 & 210 & 83.0 \\
\hline 6 & 15 & 55 & 210 & 83.5 \\
\hline 7 & 30 & 55 & 60 & 158.5 \\
\hline $8^{2)}$ & 30 & 55 & 210 & 153.3 \\
\hline $9^{3)}$ & 30 & 55 & 210 & 155.1 \\
\hline
\end{tabular}

1) Yields of vacuum-dried sodium salts of carboxymethyla
2) CM-Weeping lovegrass, and 3) CM-Canada goldenrod. material. Based on these facts, $143 \%$ of yield is considered to be a proper value. Therefore, using direct $\mathrm{CM}$ reactions for $\mathrm{TF}$, at most one aliphatic $-\mathrm{OH}$ in cellulose and $\mathrm{C} 9-\mathrm{OH}$ aliphatic $-\mathrm{OH}$ in lignocellulosics was reacted and converted into $-\mathrm{COO}^{-} \mathrm{Na}^{+}$. Interestingly, only a little decrease of yields has been observed through these processes. Although a part of hemicellulose was expected to be isolated from LC through this reaction as described in our purpose, almost all hemicellulose probably remained in TF-CM matrix. Therefore our first purpose of this reaction was quite broken. But, a resulting CM composite with almost whole components of lignocellulosics was obtained directly from wild grasses.

In order to determine adequate reaction conditions for synthesis of TF-CM materials, syntheses under different temperature (Run2-4), with different concentrations of $\mathrm{NaOH}$ (Run5-6) and with different reaction times (Run7) were carried out.

As shown in Table2 (run2), yield was down to $89.2 \%$ at $5{ }^{\circ} \mathrm{C}$ due to activation energy of $\mathrm{CM}$ reactions. But $\mathrm{CM}$ derivatives obtained at $25{ }^{\circ} \mathrm{C}$ (run3) and at $40{ }^{\circ} \mathrm{C}$ (run4) showed up to $150.2 \%$ and to $159.2 \%$ yield, respectively. That is, reaction temperature above $25{ }^{\circ} \mathrm{C}$ was required for synthesis of TF-CM. Remarkable influences were observed relatively low concentration of $\mathrm{NaOH}(7.5 \%$ and $15 \%)$ in Table2 (run5 and 6). Yields of TF-CM were only $83.0 \%$ and $83.5 \%$ under these conditions. Under these alkaline conditions, aliphatic $-\mathrm{OH}$ groups in both carbohydrates and lignin were not ionized sufficiently. But under these conditions, only phenolic $-\mathrm{OH}$ groups in lignins were changed to phenoxide ion forms for selective $\mathrm{CM}$ reactions of phenolic moieties in LC. In addition, a sufficient yield of TF-CM was obtained with reaction under the standard condition for $60 \mathrm{~min}$ (run7, Table2). Moreover, WLG (run8) and CG (run9) showed almost same yields as $\mathrm{CM}-\mathrm{TF}$ materials. Interestingly, CG-TF which is Asteraceae with different plant tissues in stems showed almost same yield. This result implied that both Gramineae and Asteraceae have similar higher order structures of macromolecular matrix in cell walls.

As shown in Fig.2, there were remarkable changes in peaks around $1700 \mathrm{~cm}^{-1}$ which corresponded to both

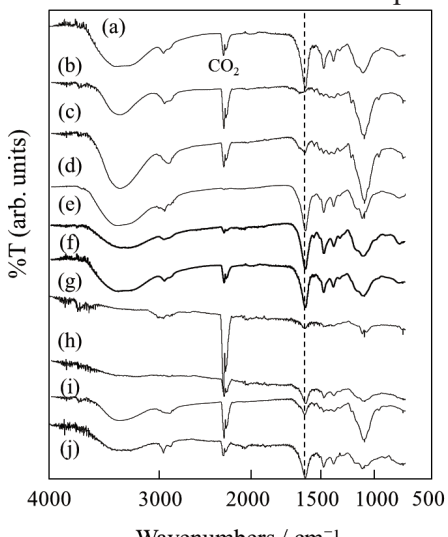

Fig.2 FT-IR spectra for carboxymethylated Tall Fescue prepared under various conditions. (a) under the standard condition, $30 \% \mathrm{NaOH}, 55^{\circ} \mathrm{C}, 3 \mathrm{~h}$, (b) $7.5 \% \mathrm{NaOH}$, (c) $15 \% \mathrm{NaOH}$, (d) reaction for $1 \mathrm{~h}$, (e) $2 \mathrm{~h}$, (f) $3.5 \mathrm{~h}$, (g) reaction temperature at 5 ${ }^{\circ} \mathrm{C}$, (h) $25{ }^{\circ} \mathrm{C}$, (i) $40{ }^{\circ} \mathrm{C}$ and (j) carboxymethylated Canada Goldenrod prepared under the standard condition. 
symmetric and asymmetric vibration modes of $-\mathrm{COO}^{-}$ ions. In addition all spectra showed around $1100 \mathrm{~cm}^{-1}$

(aliphatic ethers, stretching) , $1500 \mathrm{~cm}^{-1}$ and $1600 \mathrm{~cm}^{-1}$ (aromatic ring, $\mathrm{C}=\mathrm{C}$ stretching). As derivatives of both carbohydrates and lignins were observed in these spectra, these results indicated grafting of $\mathrm{CM}$ groups on lignocellulosics were occurred. Though $\mathrm{CM}$ derivatives, which were prepared at 25 and $40{ }^{\circ} \mathrm{C}$, showed stable high yields (Table2, run 3 and run 4), only small peaks of $-\mathrm{COO}^{-}$were observed. Also, $\mathrm{CM}$ derivatives prepared with low concentrations of $\mathrm{NaOH}$ (Table2, run 5 and 6) showed low yields and only small $-\mathrm{COO}^{-}$peaks in FT-IR. Though WLG was expected to show same tendency as Tall fescue, FT-IR spectra implied insufficient reactions because Fig.2 (i) was similar to Fig.2 (b) and (c). In addition, Canada goldenrod showed similar spectrum to Fig.2 (d)-(f), sufficient CM reaction was expected to be occurred.

\subsection{Measurements of viscosity}

Although direct $\mathrm{CM}$ reactions for plants of the Gramineae into CM derivatives have been investigated for agricultural plants of the Gramineae materials [4, 8-10], dynamic mechanical properties were not investigated sufficiently. As shown in Table3, viscosities of $1 \%$ aqueous solution of $\mathrm{CM}$ derivatives prepared from wild grasses showed lower than a commercial CMC-Na and CM- $\alpha$-cellulose of TF due to both lignin and lignocellulosic matrix. As shown in Table3, sufficient TF-CM which was prepared under $40-55^{\circ} \mathrm{C}$, $30 \% \mathrm{NaOH}$ and 1-3 hrs reaction conditions showed good viscosities. Typical TF-CM showed around 7.0 $\mathrm{mPas}$ of viscosity at $40{ }^{\circ} \mathrm{C}$, which value was similar to $\mathrm{CM}$ - $\alpha$-cellulose of TF. Almost all CM materials also showed temperature dependences. Although there were only little differences in both yields and FT-IR spectra, both WLG-CM and CG-CM showed lower viscosity than TF-CM because of differences in structures of plant tissues. This result implied that varieties of herbal plants with different biological species showed slightly different properties in viscosity.

\subsection{Charactersitics and properties of CG-CM}

As mentioned above, CG-CM materials obtained with similar yield $(155.1 \%)$ of TF-CM derivative $(143.3 \%)$ with sufficient substitutions of carboxymethyl Table3 Viscosity of $1 \%$ of aqueous dispersions of
carboxvmethvlated Tall fescue and Canada goldenrod under different temperatures.

\begin{tabular}{|c|c|c|c|}
\hline \multirow{2}{*}{ Run } & \multicolumn{3}{|c|}{ Viscosity / $\mathrm{mPa} \mathrm{s}$} \\
\hline & $10^{\circ} \mathrm{C}$ & $25^{\circ} \mathrm{C}$ & $40^{\circ} \mathrm{C}$ \\
\hline 1 & 12.2 & 8.2 & 6.3 \\
\hline 2 & 2.6 & 2.1 & 1.6 \\
\hline 3 & 5.3 & 4.0 & 3.0 \\
\hline 4 & 9.2 & 6.9 & 5.2 \\
\hline 5 & 2.0 & 1.6 & 1.1 \\
\hline 6 & 2.2 & 2.0 & 1.2 \\
\hline 7 & 9.1 & 7.0 & 5.0 \\
\hline 8 & 9.9 & 7.8 & 5.6 \\
\hline $9^{1)}$ & --- & 6.8 & 6.4 \\
\hline $10^{2)}$ & 5.7 & 3.8 & 2.8 \\
\hline $11^{3)}$ & 12.0 & 8.0 & 6.1 \\
\hline $12^{4)}$ & 37.0 & 23.6 & 19.2 \\
\hline
\end{tabular}

materials, 3) CM-holocellulose of Tall fescue and 4) commercial CMC. groups. In addition, degrees of substitution of both CG-CM and TF-CM were 0.08 and 0.11 , respectively. Therefore similar properties of CG-CM and TF-CM were expected due to similarity on structural features. But both solubility to water and viscosity of aqueous dispersions were quite different (Table3). As ratio of viscosity at $5^{\circ} \mathrm{C}(\mathrm{TF} / \mathrm{CG}=2.3)$ was slightly larger than at $40{ }^{\circ} \mathrm{C}(\mathrm{TF} / \mathrm{CG}=2.1)$, influences of inhibition on mobility was pointed out. These results indicated that $\mathrm{CM}$ reactions were mainly occurred on the surfaces of milled TF particles as Ren et al pointed out [5]. Based on these results, it was found that only information of chemical features was probably insufficient to be understood total properties of direct $\mathrm{CM}$ materials. Therefore mechanical properties such as both solubility and viscosity were also required to be understood these complicated composites. Moreover it was also important to distinguish species of wild plants for utilization of optimized applications.

\section{CONCLUSION}

$\mathrm{CM}$ reactions on weeds such as TF, CG and WLG have been succeeded directly without losing polymeric components. Although degrees of substitution of TF and CG were around 0.1, almost all components were dissolved or dispersed well in water. Therefore, these materials were able to be treated as hydrophilic macromolecular composites. Since viscosity of $1 \%$ aqueous solutions of $\mathrm{CM}$ derivatives showed dependences of both temperatures and $\mathrm{pH}$, properties of these composites behaved as ionic and hydrophilic macromolecules. Moreover, there are differences in viscosity between $\mathrm{TF}$ and $\mathrm{CG}$ but with similar degree of substitutions. These results implied separation of mixtures of grass materials was required to be obtained particular property of each grass material.

\section{ACKNOWLEDGEMENTS}

The authors thank to both North office of construction of Hiroshima prefecture and Shobara city office for permission for collection of wild grass materials.

\section{REFERRENCES}

[1] S. Seki, O. Ito and M. Funaoka, Trans. Mat. Res. Soc. Japan, 36, 1001-1004 (2002)

[2] Y. Akao, N. Seki, Y. Nakagawa, H. Yi, K. Matsumoto, K. Ito, M. Funaoka, W. Maruyama, M. Naoi, Y. Nozawa, Bioorg. Med. Chem.,12, 4791-4797(2004)

[3] S-N. Chien, H. Ren, M. Aoyagi, T. Amidon and Y-Z. Lai, J. Biobased Mater. Bioenergy, 4, 40-45(2010)

[4] H. Ren, S. Quin and S. Omori, J. Wood Sci., 61, 199-203(2015)

[5] H. Ren, M. Aoyagi, T. Amidon and Y-Z. Lai, J. Biobased Mater. Bioenergy, 5, 365-370(2011)

[6] N. Olaru, L. Olaru, A. Stoleriu and D. Timpu, J. Appl. Polym. Sci., 67, 481-486(1998)

[7] N. Olaru and L. Olaru, Macromol. Chem. Phys, 202, 207-211(2001)

[8] N. Olaru, L. Olaru, J. Appl. Polym. Sci., 67, 481-486(1998)

[9] N. Olaru, L. Olaru, Ind. Eng. Chem. Res., 43, 5057-5062(2004)

[10] S. Mansouri, R. Khiari, F. Bettaieb, A. A. El-Gendy and F. Mhenni, J. Polym. Environ., 23, 190-198(2015)

(Received July 31, 2017; Accepted January 5, 2018; Published Online February 1, 2018) 